\title{
A Dire Emergency Case of Stab Injury with Impending Ischemia of Eviscerated Bowel with Colonic Perforation - A Case Report
}

\author{
M Amir ${ }^{1}$, Sameer $D^{1}$, Prathamesh $P^{1}$ and Chatterjee $S^{1^{*}}$ \\ Bombay Hospital Institute of Medical Sciences, Bombay Hospital Avenue, Mumbai, India.
}

*Correspondence Author: Chatterjee S, Assistant Professor, Maharashtra University of health sciences,

Bombay Hospital Institute of Medical Sciences, Bombay Hospital Avenue, Mumbai, India.

Received date: April 04, 2021; Accepted date: July 19, 2021; Published date: August 30, 2021

Citation: M Amir, Sameer D, Prathamesh P and Chatterjee S, (2021) A Dire Emergency Case of Stab Injury with Impending Ischemia of Eviscerated Bowel with Colonic Perforation - A Case Report. J, Surgical Case Reports and Images 4(6); DOI: 10.31579/2690-1897/054

Copyright: ( ) 2021, Chatterjee S, This is an open access article distributed under the Creative Commons Attribution License, which permits unrestricted use, distribution, and reproduction in any medium, provided the original work is properly cited.

\begin{abstract}
Penetrating abdominal trauma is mostly caused by gunshots or stab wounds.1 Management of penetrating abdominal trauma is often challenging and time between the injury and surgical intervention play a pivotal role in such cases depending upon the clinical presentation of the patient.The success rate depends so much on early surgical intervention that one cannot wait for pre-operative work up before taking the patient to operation theatre 2 . We present a case of stab injury presented with eviscerated ischemic bowel and perforation in transverse colon with mesenteric arterial spurter.

Keywords- penetrating abdominal trauma, stab wounds, perforation, ischemic bowel, mesenteric arterial spurter
\end{abstract}

\section{Introduction}

Penetrating abdominal trauma most frequently results from gunshot wounds and stab wounds which cause significant intra-abdominal injury $[1,3]$. The most commonly injured structures include Small bowel, Liver, Colon, Abdominal, vascular structures $[4,5]$. People with penetrating abdominal trauma may have signs of hypovolemic shock and peritonitis. The treatment is dependent on many different variables such as the anatomical location and the severity of the injury ${ }^{6}$. In severe cases when homeostasis cannot be maintained the use of damage control surgery may be utilized [7].

\section{Case Report}

16 year old female brought to the emergency department with alleged history of anterior abdominal stab wound with eviscerated ischemic bowel strangulated in the stab wound. On examination Patient was hemodynamically unstable with PR-130/min B.P - 70/50mm of hg. Spo2$90 \%$ at room air. Patient was resuscitated. Decision was taken to go for emergency laparotomy. On exploration there was immediate improvement in the blood circulation to strangulated bowel. Intraoperative findings reveals injury to the mesenteric vessels which were spurting and perforation over the transverse colon from which worms were coming out .This helps us in localizing sub-centrimetric perforation in colon. Mesenteric vessels were clamped and ligated with sutures. Colonic perforation was primarily closed .Post op period was uneventful with minor surgical site infection.

\section{Declaration section}

- Ethics approval and consent to participate - Bombay hospital ethics committee

- Consent from patient - Taken

- Availability of data and materials- Not applicable

- Competing interests- No competing interests

- Funding- Not applicable

\section{Author contribution}

Study conception and design: Dr Mohd Amir

Acquisition of data: Dr Prathamesh P

Analysis and interpretation of data: Dr Sameer D

Drafting of manuscript: Dr Mohd Amir

Critical revision: Dr Chatterjee $\mathrm{S}$

\section{Conflict of interest}

None.

\section{Funding}

None. 


\section{Consent}

Consent taken from the patient for case study and publishing.

\section{References}

1. Charles K, Brohi K. (2004) Penetrating abdominal trauma: Guidelines for evaluation.

2. Mankin SL (September 1998). Emergency! Stab wound. The American Journal of Nursing. 98 (9): 49.

3. Fitzgerald, J.E.F.; Larvin, Mike (2009). Chapter 15: Management of Abdominal Trauma. In Baker, Qassim; Aldoori, Munther (eds.). Clinical Surgery: A Practical Guide. CRC Press. pp. 192204.
4. Taghavi S, Askari R. StatPearls. StatPearls Publishing; Treasure Island (FL): Jul 19, 2020. Liver Trauma. [PubMed]

5. Revell MA, Pugh MA, McGhee M. (2018) Gastrointestinal Traumatic Injuries: Gastrointestinal Perforation. Crit Care Nurs Clin North Am. 30(1):157-166.

6. Phillips B, Holzmer S, Turco L, Mirzaie M, Mause E, Mause A, Person A, Leslie SW, Cornell DL, Wagner M, Bertellotti R, Asensio JA. (2017) Trauma to the bladder and ureter: a review of diagnosis, management, and prognosis. Eur J Trauma Emerg Surg. 43(6):763-773

7. Iflazoglu N, Ureyen O, Oner OZ, et al. (2015) Complications and risk factors for mortality in penetrating abdominal firearm injuries: Analysis of 120 cases. Int J ClinExp Med. 8(4):61546162.
This work is licensed under Creative Commons Attribution 4.0 License

To Submit Your Article Click Here: Submit Manuscript

DOI: $10.31579 / 2690-1897 / 054$
Ready to submit your research? Choose Auctores and benefit from:

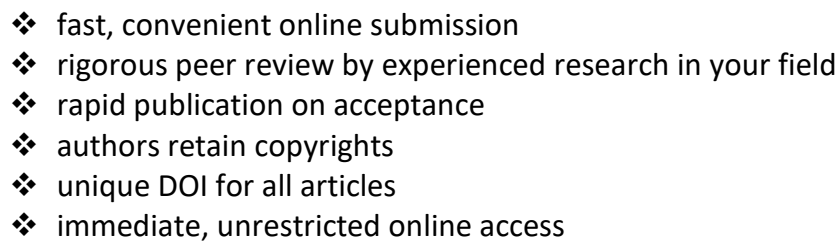

At Auctores, research is always in progress.

Learn more auctoresonline.org/journals/journal-of-surgical-case-reportsand-images 